\title{
Model evaluation and optimisation of nutrient removal potential for sequencing batch reactors
}

\author{
N Artan ${ }^{1 *}$, P Wilderer ${ }^{2}$, D Orhon ${ }^{1}$, R Tasli' and E Morgenroth ${ }^{3}$ \\ ${ }^{1}$ Environmental Engineering Department, Istanbul Technical University, I.T.U. Insaat Fakültesi, 80626 Maslak, Istanbul, Turkey \\ ${ }^{2}$ Institute of Water Quality Control and Waste Management, Technical University of Munich, D-85748 Munich, Germany \\ ${ }^{3}$ Department of Civil and Eniron. Engineering, University of Illinois at Urbana-Champaign, 3219 Newmark Civil Engineering Lab., 205 \\ North Mathews Avenue, MC-250, Urbana, IL, 61801, USA
}

\begin{abstract}
Performance of sequencing batch reactors for simultaneous nitrogen and phosphorus removal is evaluated by means of model simulation, using the activated sludge model, ASM2d, involving anoxic phosphorus uptake, recently proposed by the IAWQ Task group. The evaluation includes all major process configurations with different aerobic, anoxic, anaerobic sequences, and fill conditions. Basic relationships between modelling and design based on overall process stoichiometry are established for the interpretation of nutrient profiles associated with different operation modes. A similar approach is also used for the assessment of the effect of major operating parameters on system performance.
\end{abstract}

\section{Introduction}

The SBR technology, despite its simplicity as a batch reactor, offers a great flexibility of operation where the sequence of successive phases can be adjusted to sustain any desired combination of growth conditions for different biochemical processes (Irvine et al., 1997; Ketchum, 1997; Morgenroth and Wilderer, 1998). This feature is particularly significant for simultaneous nitrogen and phosphorus removal, now a prerequisite for most wastewaters. The process is an attractive research tool as the batch operation is most suitable for the observation and interpretation of transient responses of any selected process component. It is also used in practice at an increasing pace, as an effective biological treatment technology for a large spectrum of various wastes, ranging from simple domestic sewage to different industrial effluents (Goronszy, 1995; Artan et al., 1996; Wilderer et al., 2001).

Biological nutrient removal involves an intricate array of biochemical processes to be sustained in an appropriate sequence of aerobic, anoxic and anaerobic conditions. The number of processes and components together with the complexity of SBR hydraulics makes it impossible to come up with an accurate prediction of effluent quality, without the use of appropriate modelling. Simulation programs based on models reflecting microbial behaviour with reasonable accuracy are now regarded as valuable tools to systematically assess various design and operating strategies, thus allowing for system optimisation. In the last years, a number of modelling approaches has been proposed for this purpose. For example the IWA (formerly IAWQ) Task Group has developed the Activated Sludge Model No.2 (ASM2) incorporating EBPR (Henze et al., 1995). These models, while providing an acceptably reliable description for nitrogen transformations, generally lacked sufficient credibility for the fate of phosphorus, mainly because they did not incorporate sufficient experimental support, and also, the behaviour of phosphate accumulating

\footnotetext{
* To whom all correspondence should be addressed. 푱 902122856547 ; fax 902122853793 ; e-mail: nartan@ srv.ins.itu.edu.tr Received 24 July 2001; accepted in revised form 8 July 2002.
}

organisms (PAOs) did not always appear quite predictable (Sorm et al., 1996; Kuba et al., 1997; Ekama and Wentzel, 1999). In the light of recent research (Mino et al., 1995; Artan et al., 1998; Barker and Dold, 1997), ASM2 was modified as ASM2d to include denitrification by PAOs with reduced anoxic P uptake (Henze et al., 1999).

Model simulation of SBR performance provides information for a selected set of different operating conditions. Interpretation of the simulation results for process design is only meaningful when support is provided in terms of relevant process stoichiometry and mass balance relationships for related model components. The basic stoichiometry of nitrogen oxidation and removal is well understood; it was recently translated into a rational design procedure for SBR systems (Artan et al., 2001). A similar approach is yet to be developed for excess biological phosphorus removal (EBPR), due to the complexity of processes and the excessive number of process components involved. Therefore, evaluation of the fate of nitrogen and phosphorus forms competing for the same organic carbon source in the anoxic/anaerobic phases, within the simultaneous N/P removal systems, still requires model simulation.

The objective of this study was to evaluate the performance of SBRs for simultaneous nitrogen and phosphorus removal by means of model simulation, using the activated sludge model, ASM2d. The evaluation included all major process configurations with different aerobic, anoxic, anaerobic sequences, and fill conditions. Basic relationships between modelling and design based on overall process stoichiometry were established for the interpretation of nutrient profiles associated with different operation modes. A similar approach was used for the assessment of the effect of major operating parameters on system performance. The impact of anoxic $\mathrm{P}$ uptake on process performance was also reviewed by comparing ASM2d with ASM2.

\section{Conceptual approach for model simulation}

\section{Reactor kinetics}

Mechanistic understanding of the SBR process is best secured by identifying significant operational parameters and by interpreting 
them in a way that allows comparison with respect to continuous flow systems. The striking feature of the system is that it involves a single reactor both for biochemical processes and solid-liquid separation taking place in a temporal sequence of engineered cycles.

The total cycle time, $\mathrm{T}_{\mathrm{C}}$, is basically the sum of five phases, namely fill, $\mathrm{T}_{\mathrm{F}}$, react, $\mathrm{T}_{\mathrm{R}}$, settling, $\mathrm{T}_{\mathrm{S}}$, draw, $\mathrm{T}_{\mathrm{D}}$, and idle, $\mathrm{T}_{\mathrm{I}}$, phases. Biological processes are assumed to take place only during the process period, $\mathrm{T}_{\mathrm{P}}$, corresponding to the sum of fill and react phases. In nutrient removal SBR systems, the process phase includes an aerated period, $\mathrm{T}_{\mathrm{A}}$ and a mixed period, $\mathrm{T}_{\mathrm{M}}$. Depending on the presence or absence of nitrate in the mixed liquor, the portions of the mixed period can be anoxic $\left(\mathrm{T}_{\mathrm{DN}}\right)$ or anaerobic $\left(\mathrm{T}_{\mathrm{AN}}\right)$.

The wastewater is introduced and held in the reactor under different conditions necessary for the desired package of biochemical processes, allowed to settle and finally removed from the reactor for the start of a new cycle. Consequently, an important parameter to be considered is the required volumetric capacity; the total reactor volume, $V_{T}$, consists of a stationary or an initial volume, $V_{0}$, that basically holds the settled biomass with a safety margin and a fill volume, $V_{F}$, corresponding to the volume of wastewater filled and discharged in each cycle. In this context, SBR may be regarded as a single tank activated sludge plant with a cyclic operation and a variable volume within the fill phase which may be selected as the desired portion of the operation cycle. During the fill phase, biochemical reactions take place in a reactor volume that gradually increases from an initial level, $\mathrm{V}_{0}$, to the total reactor volume, $\mathrm{V}_{\mathrm{T}}$, defined as

$$
V_{T}=V_{0}+Q T_{F}
$$

where:

$$
\mathrm{Q}=\text { flow rate }
$$

For the fill phase, the mass balance for each model component, $\mathrm{C}_{\mathrm{i}}$, may be formulated as follows, with the understanding that an SBR always operates as a completely mixed reactor,

$$
\frac{d\left[V C_{i}\right]}{d t}=Q C_{i 1}+V r_{i}
$$

where:

$$
\begin{aligned}
& \mathrm{V}=\text { reactor volume at a given time, } \mathrm{t} \\
& \mathrm{C}_{\mathrm{i} 1}=\text { influent } \mathrm{C}_{\mathrm{i}} \text { concentration } \\
& \mathrm{r}_{\mathrm{i}}=\text { observed conversion rate for } \mathrm{C}_{\mathrm{i}}
\end{aligned}
$$

By definition:

$$
\frac{d V}{d t}=Q
$$

Taking the differential of the left-hand side and rearranging to include the above definition, Eq. (2) may be written as:

$$
\frac{d C_{i}}{d t}=\frac{Q\left(C_{i 1}-C_{i}\right)}{V_{0}+Q t}+r_{i}
$$

During the react portion of the process period where the SBR functions as a completely mixed batch reactor of constant volume, mass balance equations are reduced to the following expression:

$$
\frac{d C_{i}}{d t}=r
$$

Mass balances for all the model components may be written as a set of coupled ordinary differential equations, which are non-linear for the generally accepted reaction kinetics. As the reaction term for any selected model component may be a function of the concentrations of several other components, it is generally necessary to solve these mass balance equations simultaneously. For the rate expressions associated with the adopted models, these differential expressions can be integrated over the duration of the cycle to determine the concentration profiles of the model components during the cycle. Numerical integration techniques are usually required for the solution of these equations.

With the commonly accepted assumption that no biological conversion takes place during settling, draw and idle phases, the concentration of a soluble component at the end of the react phase remains the same at the end of the cycle; the concentration of a particulate component, however, is bound to change due to sludge waste securing cyclic steady-state operation. Assuming that excess sludge is wasted at the end of the react phase at the rate dictated by the selected sludge age, $\theta_{x}$, and settling is ideal with no carry-over of suspended solids in the effluent stream, the concentration of any particulate component at the beginning of the next cycle, $\mathrm{X}_{\mathrm{i} 0}$, can be calculated from the following mass balance expression:

$$
X_{i 0}=\frac{V_{T} X_{i e}\left(1-1 / m \theta_{X}\right)}{V_{0}}
$$

where:

$$
\begin{aligned}
X_{\mathrm{ie}}= & \text { concentration of any particulate component at the end } \\
& \text { of the react phase } \\
\mathrm{m}= & \text { number of cycles per day }
\end{aligned}
$$

The system will reach a cyclic steady-state through continuous operation in the sense that the progression of each cycle remains identical to any other and therefore, the initial concentration of a soluble component, $\mathrm{S}_{\mathrm{i} 0}$, becomes equal to the concentration of the same component at the end of the cycle, $\mathrm{S}_{\mathrm{ie}}$.

The number of model components, $i$, may range from three in simple models for carbon removal alone, to double figures as in complex models for nutrient removal, depending on whatever purpose the model is expected to serve. The reaction term, $r_{i}$, represents the sum of all the rates for all the $j$ number of processes in which the model component $i$ participates, where $j$ may also vary according to the complexity of the model. The selected biokinetic model can be implemented in various computer codes for the simulation of the behaviour of SBR systems.

\section{Basis for model simulation}

In this study, ASM2d implemented by AQUASIM (Reichert, 1994) was used for the simulation of nutrient removal in SBR systems. Simulations were carried out with the assumption that the mixed liquor dissolved oxygen concentration would be zero during the mixed periods, instantaneously rising to its set point concentration of $S_{0}=6.0 \mathrm{mg} \cdot \ell^{-1}$ at the start of the subsequent aerobic period.

An influent wastewater composition, mainly consisting of a total $\mathrm{COD}=260 \mathrm{mg} \cdot \ell^{-1}, \mathrm{TKN}=25 \mathrm{mg} \cdot \ell^{-1}$ and total $\mathrm{P}=6 \mathrm{mg} \cdot \ell^{-1}$, together with their fractionation into soluble and particulate model components, and the entire spectrum of kinetic and stoichiometric coefficients, suggested as default values at $20^{\circ} \mathrm{C}$ in ASM2d, were selected for the simulation runs. The basic design of SBR systems required to run the simulation program, was performed in accordance with the rational design approach formulated by Artan et al. (2001). An effective sludge age value of $\theta_{\mathrm{XE}}=15 \mathrm{~d}$ was adopted as a constant design parameter for all the simulation runs. The model simulation was performed with three different aeration ratios, $\mathrm{T}_{\mathrm{A}} / \mathrm{T}_{\mathrm{P}}$, in the range of 0.4 to 0.6 , all corresponding to aerobic sludge age values to ensure complete nitrification. One hour was devoted to settle, draw and idle phases in each cycle, $\left(T_{S}+T_{D}+T_{I}=1.0 \mathrm{~h}\right)$, so 
that the total sludge retention time, $\theta_{\mathrm{X}}$ could be calculated as below:

$$
\theta_{X}=\frac{\theta_{X E} T_{C}}{T_{C}-1}
$$

Three different cycle times, $\mathrm{T}_{\mathrm{C}}$, of 4.0, 4.8 and $6.0 \mathrm{~h}$ were selected to ensure appropriate reactor volume operated with reasonable MLSS levels. The cycle times resulted in nominal hydraulic retention time, $\mu \mathrm{h}$, in close vicinity of $0.45 \mathrm{~d}$ $(10.8 \mathrm{~h})$ based on the selected sludge volume index (SVI) for adopted wastewater composition and sludge age. This value of $\theta \mathrm{h}=0.45$ $\mathrm{d}$ was used and held constant for all the runs, mainly to visualise the effect of other operational conditions on the nutrient removal performance of SBR systems. In this context, three different $\mathrm{V}_{0} / \mathrm{V}_{\mathrm{F}}$ ratios could be computed, based on the selected cycle times, for the same hydraulic retention time, according to the equation below:

$$
\theta_{h}=T_{C} \frac{V_{T}}{V_{F}}=\left(1+\frac{V_{0}}{V_{F}}\right) T_{C}
$$

The rational design procedure also allows for the calculation of three basic parameters for nitrogen removal, namely, nitrification capacity, $\mathrm{N}_{\mathrm{OX}}$, denitrification potential, $\mathrm{N}_{\mathrm{DP}}$, and available nitrate, $\mathrm{N}_{\mathrm{A}}$, thus providing a basis for the evaluation of simulation results concerning both $\mathrm{N}$ and $\mathrm{P}$ removal competing for the same organic carbon source. In this study, the nitrification capacity, $\mathrm{N}_{\mathrm{ox}}$, reflecting the concentration of ammonia nitrogen oxidised or the nitrate nitrogen produced could be calculated from mass balance for TKN as $\mathrm{N}_{\mathrm{OX}}=20 \mathrm{mg} \cdot \ell^{-1}$, for the selected effective sludge age of $\theta_{\mathrm{XE}}=15$ $\mathrm{d}$, assuming complete nitrification. This $\mathrm{N}_{\mathrm{OX}}$ value could be accepted as approximately constant for all runs.

An important parameter in designing nitrogen removal systems is the denitrification potential, $\mathrm{N}_{\mathrm{DP}}$, defining the nitrate concentration that may be potentially removed through oxidation of available organic carbon during the anoxic phase. This parameter is conveniently defined as the fraction of the nitrate nitrogen equivalent of the total electron acceptor demand associated with the organic carbon removal (Orhon and Artan, 1994; Artan et al., 1995). For SBR systems, $\mathrm{N}_{\mathrm{DP}}$ may be calculated in two different ways, based on filling and aeration patterns, for the selected mixing ratio, $\mathrm{T}_{M} / \mathrm{T}_{\mathrm{P}}$ : It may be defined with the expression below, assuming an even distribution of electron acceptor demand throughout the aerobic and anoxic periods:

$$
N_{D P}=\left(\frac{T_{M}}{T_{P}}\right) \eta\left(1-Y_{N H}\right) \frac{C_{S 1}}{2.86}
$$

where:

$$
\begin{array}{ll}
\mathrm{T}_{\mathrm{M}} / \mathrm{T}_{\mathrm{P}} & =\text { mixing period to process period ratio } \\
\mathrm{C}_{\mathrm{S} 1} & =\text { influent biodegradable substrate, } \mathrm{M} \mathrm{COD} \mathrm{L} \mathrm{L}^{-3} \\
\mathrm{Y}_{\mathrm{NH}} & =\text { observed heterotrophic yield, cell COD }(\mathrm{COD})^{-1} \\
\eta & =\text { correction factor for anoxic respiration }
\end{array}
$$

When filling is performed only during the anoxic periods, the expression for $\mathrm{N}_{\mathrm{DP}}$ needs to be rearranged as follows, with the stipulation that the entire electron acceptor demand associated with growth on influent readily biodegradable substrate, $\mathrm{S}_{\mathrm{S} 1}$ is exerted in the anoxic periods and the remaining portion is distributed between the anoxic and aerobic periods in accordance with the $\mathrm{T}_{\mathrm{M}} /$ $\mathrm{T}_{\mathrm{P}}$ ratio:
TABLE 1

used in simulation studies and calculated values of $\mathrm{N}_{D P}$ and $\mathrm{N}_{A}$

\begin{tabular}{|c|c|l|l|c|c|}
\multicolumn{7}{|c|}{ values of $\mathbf{N}_{\mathrm{DP}}$ and $\mathbf{N}_{\mathbf{A}}$} \\
\hline $\mathbf{V}_{\mathbf{0}} \mathbf{V}_{\mathbf{F}}$ & $\mathbf{T}_{\mathrm{M}} / \mathbf{T}_{\mathbf{P}}$ & Filling pattern & $\begin{array}{l}\text { Aeration } \\
\text { pattern }\end{array}$ & $\begin{array}{c}\mathbf{N}_{\mathrm{DP}} \\
\left(\mathbf{m g} \cdot \ell^{-1}\right)\end{array}$ & $\begin{array}{c}\mathbf{N}_{\mathbf{A}} \\
\left(\mathbf{m g} \cdot \ell^{-1}\right)\end{array}$ \\
\hline 1.7 & 0.5 & Single mixed & Single & 22 & 12.6 \\
1.25 & 0.5 & Single mixed & Single & 22 & 11.1 \\
0.8 & 0.5 & Single mixed & Single & 22 & 8.9 \\
0.8 & 0.4 & Single mixed & Single & 17.6 & 8.9 \\
0.8 & 0.6 & Single mixed & Single & 25.7 & 8.9 \\
0.8 & 0.6 & Single mixed & Double & 23.3 & - \\
0.8 & 0.6 & Double mixed & Double & 25.7 & - \\
0.8 & 0.6 & Dump & Intermittent & 23.3 & - \\
0.8 & 0.6 & Continuous & Intermittent & 23.3 & - \\
0.8 & 0.4 & Continuous & Intermittent & 15.5 & - \\
\hline
\end{tabular}

$$
N_{D P}=\left(\frac{T_{M}}{T_{P}}\right) \eta\left(1-Y_{N H}\right) \frac{C_{S 1}}{2.86}+\left(\frac{T_{A}}{T_{P}}\right) \eta\left(1-Y_{N H}\right) \frac{S_{S 1}}{2.86}
$$

where:

$$
\begin{aligned}
\mathrm{T}_{\mathrm{A}} / \mathrm{T}_{\mathrm{P}}= & \text { aeration period to process period ratio } \\
\mathrm{S}_{\mathrm{S} 1}= & \text { influent readily biodegradable substrate, } \\
& \mathrm{M} \mathrm{COD} \mathrm{L}^{-3}
\end{aligned}
$$

The available nitrate, $\mathrm{N}_{\mathrm{A}}$, is the other significant parameter to assess the performance of nitrogen removal in single sludge reactors. In view of the fact that only the nitrate remaining with the volume $\mathrm{V}_{0}$ at the end of the previous cycle can be available for predenitrification, $\mathrm{N}_{\mathrm{A}}$ may be defined with the following expression for SBR systems:

$$
N_{A}=\frac{V_{0}}{V_{T}} N_{O X}=\frac{V_{0} / V_{F}}{\left(1+V_{0} / V_{F}\right)} N_{O X}
$$

The various operating strategies used in the simulation studies are outlined in Table 1 . The model simulation basically involved 10 runs with different operation conditions. A fill time ratio, $\mathrm{T}_{\mathrm{F}} / \mathrm{T}_{\mathrm{C}}$, of $1 / 3$ is selected for all runs except for Runs 8, 9 and 10. In Runs 9 and 10, filling is maintained during the whole cycle time except for the settle and draw phases while in Run 8 dump filling is applied. Table 1 also lists predicted values of the denitrification potential, $\mathrm{N}_{\mathrm{DP}}$, calculated from expressions 9 or 10 depending on filling and aeration patterns, together with the available nitrate values $\mathrm{N}_{\mathrm{A}}$ only applicable to operating modes that can be identified as predenitrification systems. The respective $\mathrm{N}_{\mathrm{DP}}$ and $\mathrm{N}_{\mathrm{A}}$ values given in Table 1 set the basis for evaluating model simulation of system performance using process stoichiometry, as elaborated in detail in the following section.

\section{Evaluation of simulation results}

The $\mathrm{S}_{\mathrm{PO} 4} \mathrm{~S}_{\mathrm{NO}}$ and $\mathrm{S}_{\mathrm{NH}}$ profiles associated with the cyclic operation of the SBR systems at steady state are illustrated in Fig. 1. Significant results of the study are also shown in Table 2, in a way to allow comparative evaluation of the effect of different operating parameters on simulated nutrient removal performance. Values of the soluble components in the Table 2 reflect effluent quality. Total suspended solids, $\mathrm{X}_{\mathrm{TSS}}$, were calculated from particulate model components, in accordance with the stoichiometric coefficients proposed in ASM2d, as indicated by the following expression: 


\begin{tabular}{|c|c|c|c|c|c|c|c|c|}
\hline \multicolumn{9}{|c|}{$\begin{array}{c}\text { TABLE } 2 \\
\text { Selected results of the simulation studies }\end{array}$} \\
\hline RUN & $\underset{\left(\mathrm{mg} \cdot \ell^{-1}\right)}{\mathrm{S}_{\mathrm{P}^{-1}}}$ & $\begin{array}{c}\mathbf{S}_{\mathrm{NH}} \\
\left(\mathbf{m g} \cdot \ell^{-1}\right)\end{array}$ & $\begin{array}{c}\mathrm{S}_{\mathrm{NO}} \\
\left(\mathbf{m g} \cdot \ell^{-1}\right)\end{array}$ & $\begin{array}{l}\text { MLSS } \\
\left(\mathbf{m g} \cdot \ell^{-1}\right)\end{array}$ & $\begin{array}{c}\text { Pcont }(\%) \\
\text { P/TSS }\end{array}$ & $\begin{array}{c}(\%) \\
\mathrm{X}_{\mathrm{PAO}} / \mathrm{TSS}\end{array}$ & $\begin{array}{l}\text { EBPR } \\
\left(\mathbf{m g} \cdot \ell^{-1}\right)\end{array}$ & $\begin{array}{l}\mathrm{N}_{\mathrm{ox}}-\mathrm{S}_{\mathrm{No}} \\
\left(\mathrm{mg} \cdot \ell^{-1}\right)\end{array}$ \\
\hline 1 & 3.16 & 0.07 & 7.3 & 3515 & 3.7 & 6.6 & 1.5 & 12.7 \\
\hline 2 & 1.86 & 0.06 & 8.8 & 3510 & 5.0 & 10.9 & 2.8 & 11.2 \\
\hline 3 & 0.65 & 0.06 & 10.9 & 3498 & 6.2 & 14.7 & 4.1 & 9.1 \\
\hline $3 a$ & 2.92 & 0.05 & 17.6 & 3228 & 3.9 & 6.9 & 1.8 & 14.4 \\
\hline $4 a$ & 1.91 & 0.11 & 8.7 & 3318 & 4.9 & 10.8 & 2.8 & 11.3 \\
\hline 5 & 0.02 & 0.10 & 10.9 & 3574 & 6.5 & 20.2 & 4.7 & 9.1 \\
\hline $5 \mathrm{a}$ & 2.2 & 0.04 & 10.9 & 3694 & 7.4 & 18.7 & 5.5 & 9.1 \\
\hline 6 & 0.45 & 0.07 & 7.8 & 3517 & 6.3 & 15.8 & 4.3 & 12.2 \\
\hline $6 a$ & 3.36 & 0.07 & 7.7 & 3542 & 6.5 & 15.7 & 4.3 & 12.3 \\
\hline $6 \mathrm{~b}$ & 3.69 & 0.05 & 8.6 & 3538 & 6.1 & 14.5 & 4.0 & 11.4 \\
\hline 7 & 0.32 & 0.31 & 6.3 & 3530 & 6.3 & 16.0 & 4.4 & 13.7 \\
\hline 8 & 4.71 & 0.10 & 2.2 & 2925 & 1.8 & 0.3 & 0 & 17.8 \\
\hline 9 & 4.68 & 0.76 & 2.1 & 2913 & 1.9 & 0.3 & 0 & 17.9 \\
\hline 10 & 4.69 & 0.36 & 5.2 & 2894 & 1.7 & 0.0 & 0 & 14.8 \\
\hline
\end{tabular}

$X_{T S S}=0.9\left(X_{H}+X_{A}+X_{P A O}\right)+0.75 X_{S}+0.75 X_{I}+0.60 X_{P H A}+3.23 X_{P P}$

where:

$\mathrm{X}_{\mathrm{TSS}}=$ total suspended solids, $\mathrm{M}(\mathrm{TSS}) \mathrm{L}^{-3}$

$\mathrm{X}_{\mathrm{H}}, \mathrm{X}_{\mathrm{A}}, \mathrm{X}_{\mathrm{PAO}}=$ heterotrophic, autotrophic and phosphate accumulating organisms, $\mathrm{M}(\mathrm{COD}) \mathrm{L}^{-3}$

$\mathrm{X}_{\mathrm{S}}=$ slowly biodegradable substrate, $\mathrm{M}(\mathrm{COD}) \mathrm{L}^{-3}$

$\mathrm{X}_{\mathrm{I}} \quad=$ inert particulate organic material, $\mathrm{M}(\mathrm{COD}) \mathrm{L}^{-3}$

$\mathrm{X}_{\mathrm{PHA}}=$ stored poly-hydroxy-alkanoates, $\mathrm{M}(\mathrm{COD}) \mathrm{L}^{-3}$

$\mathrm{X}_{\mathrm{PP}} \quad=$ stored poly-phosphate, $\mathrm{M}(\mathrm{P}) \mathrm{L}^{-3}$

The MLSS values in Table 2 represent the corresponding $\mathrm{X}_{\mathrm{TSS}}$ levels in the reactor at the end of the reaction phase. Similarly, as defined in ASM2d, the phosphorus content of the sludge was computed as

$$
P_{\text {cont }}=\frac{i_{P B M}\left(X_{H}+X_{A}+X_{P A O}\right)+i_{P X I} X_{I}+X_{P P}}{X_{T S S}}
$$

where:

$\begin{aligned} \mathrm{i}_{\mathrm{PBM}} & =\mathrm{P} \text { fraction of biomass } \\ \mathrm{i}_{\mathrm{PXI}} & =\mathrm{P} \text { content of } \mathrm{X}_{\mathrm{I}}\end{aligned}$

\section{Effect of cycle time}

The effect of cycle time on nutrient removal performance was analysed and demonstrated with the first three runs, where $T_{C}$ was increased from $4 \mathrm{~h}$ in Run 1 to $4.8 \mathrm{~h}$ and $6.0 \mathrm{~h}$ in Runs 2 and 3 respectively. As shown in Table 2, an increase in the cycle times for a constant hydraulic retention time, $\theta_{\mathrm{h}}$, inevitably results in lower $\mathrm{V}_{0} / \mathrm{V}_{\mathrm{F}}$ ratios, a key parameter comparable to the sludge recycle ratio in continuous-flow systems, and consequently, in lower $\mathrm{N}_{\mathrm{A}}$ levels. The fate of nitrogen closely depends upon the balance between $\mathrm{N}_{\mathrm{DP}}$ and $\mathrm{N}_{\mathrm{A}}$ within the non-aerated phase with the assumption that full nitrification is secured in the aerobic phase, and the lower one acts as the limiting parameter in setting the effluent nitrate concentration, $\mathrm{S}_{\mathrm{NO}}$. As the process stoichiometry yields $\mathrm{N}_{\mathrm{DP}}>\mathrm{N}_{\mathrm{A}}$ for these runs all simulating a predenitrification configuration, the $\mathrm{S}_{\mathrm{NO}}$ levels increase from $7.3 \mathrm{mg} \cdot \ell^{-1}$ to $10.9 \mathrm{mg} \cdot \ell^{-1}$ as the selected cycle time increases, indicated by the following expression:

$$
S_{N O}=N_{O X}-N_{A}=\frac{N_{O X}}{\left(1+V_{0} / V_{F}\right)}
$$

It should be noted that SBR systems do not have the same operation flexibility for simultaneous $\mathrm{N}$ and $\mathrm{P}$ removal as continuous-flow configurations in the sense that an anoxic phase is inherently established before truly anaerobic conditions: If $\mathrm{N}_{\mathrm{DP}}<\mathrm{N}_{\mathrm{A}}$, the nonaerated phase, $\mathrm{T}_{\mathrm{M}}$, becomes fully anoxic with an $\mathrm{S}_{\mathrm{NO}}$ surplus, where denitrification preferentially consumes available organic carbon, thus blocking biological processes related to EBPR; if $\mathrm{N}_{\mathrm{DP}}>\mathrm{N}_{\mathrm{A}}$, as simulated in these runs, $S_{N O}$ is fully depleted, allowing for development of a subsequent anaerobic phase within the nonaerated (mixed) period. A relatively high amount of nitrate nitrogen introduced into the mixed period is likely to result in a longer anoxic phase, with a following anaerobic phase too short for an effective EBPR, an operation mode illustrated by Run 1, where an effluent $P$ concentration of not lower than $3.16 \mathrm{mg} \cdot \ell^{-1}$ could be obtained. In SBR systems operated with filling and aeration patterns approximating predenitrification, a compromise is often needed between a lower nitrogen removal efficiency and an effective EBPR. In fact, $\mathrm{S}_{\mathrm{PO} 4}$ could be reduced to $0.65 \mathrm{mg} \cdot \ell^{-1}$ in Run 3, at the expense of a higher cycle time and lower $\mathrm{V}_{0} / \mathrm{V}_{\mathrm{F}}$ ratio, and consequently a lower $\mathrm{N}$ removal efficiency. The increase in the $\mathrm{P}$ content and the PAO fraction of the MLSS should also be observed as signs of improved EBPR in Run 3.

\section{Effect of $\mathrm{T}_{\mathrm{M}} / \mathrm{T}_{\mathrm{P}}$ ratio}

Simulation results of 5 different runs (Runs 3, 4, 5, 9, and 10) were used to evaluate the effect of $\mathrm{T}_{\mathrm{M}} / \mathrm{T}_{\mathrm{P}}$ ratio on nutrient removal performance. $\mathrm{T}_{\mathrm{C}}$ was maintained as $6 \mathrm{~h}$ and $\mathrm{V}_{0} / \mathrm{V}_{\mathrm{F}}$ ratio as 0.8 in all the runs. As previously mentioned, Runs 3, 4 and 5 were all simulated as single mixed, predenitrification systems with $\mathrm{N}_{D P}$ levels highly exceeding $\mathrm{N}_{\mathrm{A}}$ to allow simultaneus $\mathrm{P}$ removal. Therefore, the available nitrate was rate-limiting and increasing the $\mathrm{T}_{\mathrm{M}} / \mathrm{T}_{\mathrm{P}}$ ratio from 0.4 to 0.6 did not exert, as expected, any influence on the effluent nitrate nitrogen concentration which remained constant as $10.9 \mathrm{mg} \cdot \ell^{-1}$, a level directly corresponding to the selected $\mathrm{V}_{0} / \mathrm{V}_{\mathrm{F}}$ ratio. The duration of the anaerobic phase during the 


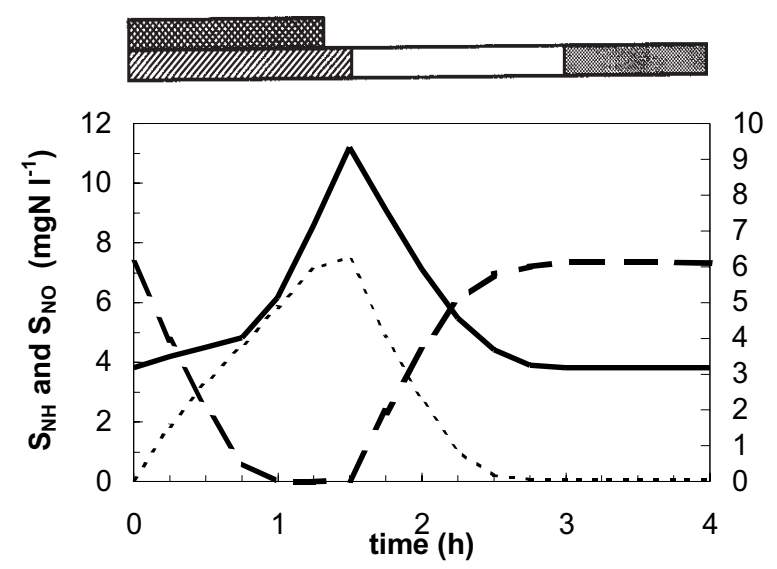

Run 1

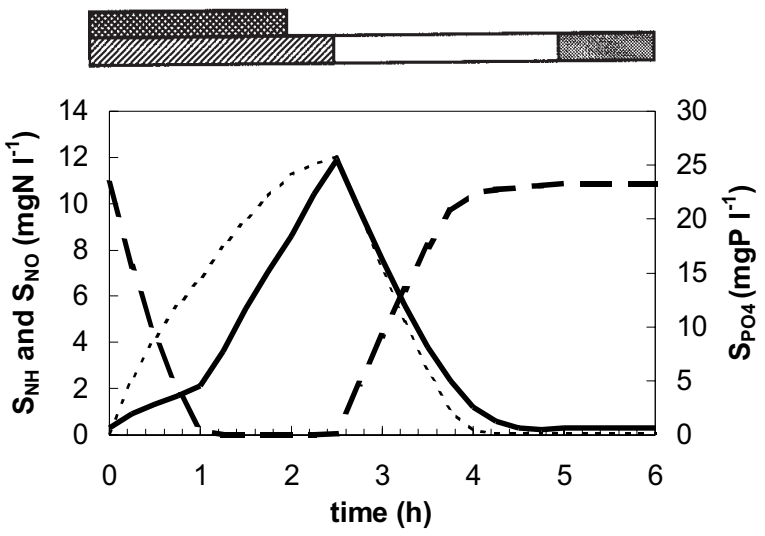

Run 3



Run 4

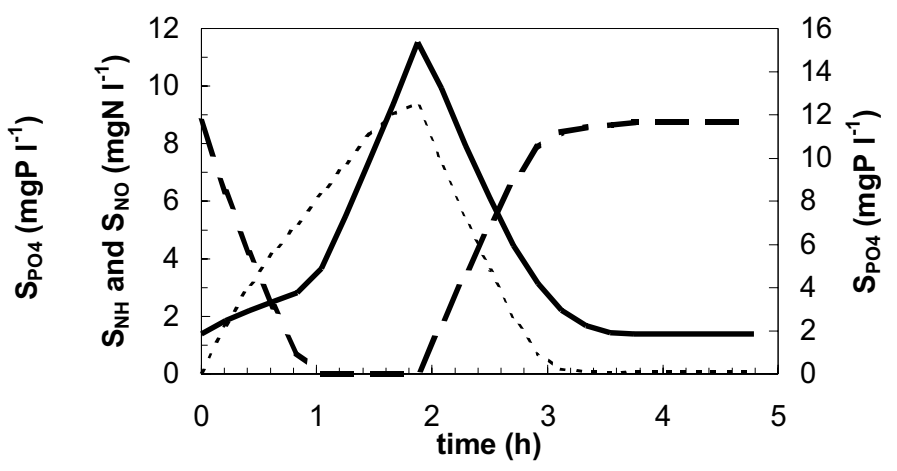

Run 2

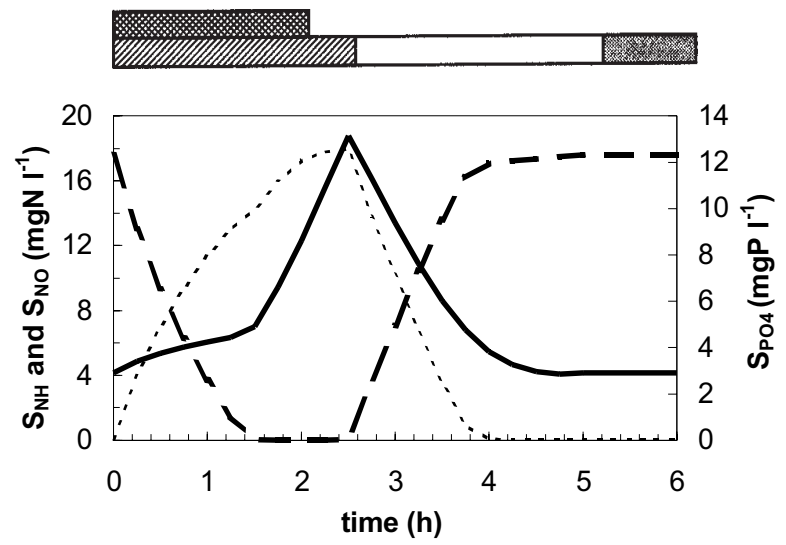

Run 3a

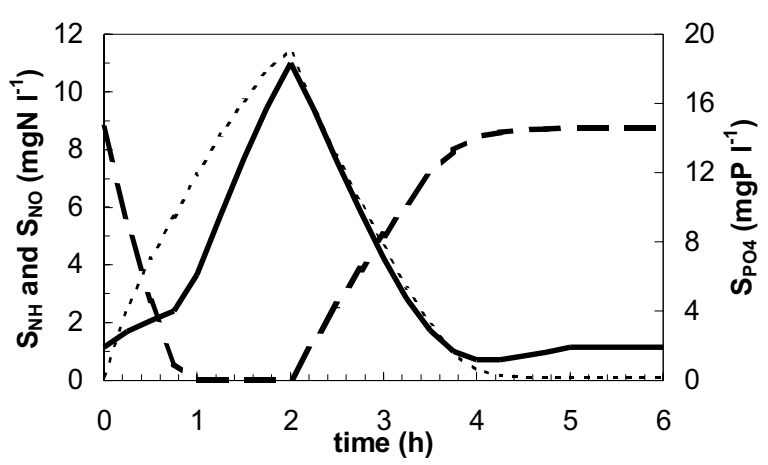

Run 4a

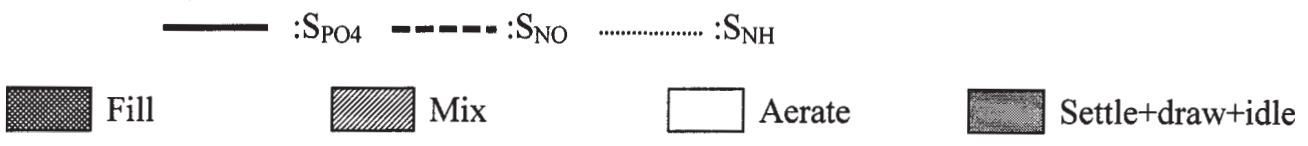

Figure 1

Nitrogen and phosphate concentration profiles (to be continued on next page)

mixed period is, however, a significant parameter for EBPR, and consequently, the effluent $\mathrm{P}$ concentration was lowered from 3.39 $\mathrm{mg} \cdot \ell^{-1}$ to $0.02 \mathrm{mg} \cdot \ell^{-1}$ with higher $\mathrm{T}_{\mathrm{M}} / \mathrm{T}_{\mathrm{P}}$ ratios, due to longer anaerobiosis.
Runs 9 and 10 simulate operation with intermittent aeration with continuous filling throughout the entire process time, $\mathrm{T}_{\mathrm{p}}$. In this type of SBR configuration, available nitrate is not solely adjusted by the $\mathrm{V}_{0} / \mathrm{V}_{\mathrm{F}}$ ratio; it is also created within each sub-cycle, 



$\mathrm{T}_{\mathrm{SC}}$, of the intermittent aeration. The $\mathrm{T}_{\mathrm{M}} / \mathrm{T}_{\mathrm{P}}$ ratio has a strong influence on the balance between $\mathrm{N}_{\mathrm{DP}}$ and the available nitrate in the sub-cycles and hence it has a controlling effect on the effluent quality: As shown in Table 2, an increase in the $\mathrm{T}_{\mathrm{M}} / \mathrm{T}_{\mathrm{P}}$ ratio from
0.4 to 0.6 , reduced the effluent nitrate concentration from $5.2 \mathrm{mg} \cdot \ell^{-1}$ in Run 10 to $2.2 \mathrm{mg} \cdot \ell^{-1}$ in Run 9, together with a slight increase in the ammonia concentration.

$\mathrm{A} \mathrm{T}_{\mathrm{M}} / \mathrm{T}_{\mathrm{P}}$ ratio of 0.4 in Run 10 was observed to provide an $\mathrm{N}_{\mathrm{DP}}$ 
lower than the available nitrate in each sub-cycle; since $\mathrm{N}_{\mathrm{DP}}$ was limiting and entirely used for denitrification, no EBPR could be achieved and the effluent nitrate concentration could be calculated with an acceptable approximation as follows:

$$
S_{N O}=N_{O X}-N_{D P}
$$

Comparing of the $\mathrm{S}_{\mathrm{N} 0}$ value calculated from Eq.(15) with the simulated effluent nitrate concentration reflects the agreement between the model simulation and the value stoichiometrically determined for $\mathrm{N}_{\mathrm{DP}}$.

A higher $\mathrm{T}_{\mathrm{M}} / \mathrm{T}_{\mathrm{P}}$ ratio of 0.6 in Run 9 , generated however an $\mathrm{N}_{\mathrm{DP}}$ in each anoxic phase, sufficient to remove all the nitrate produced in the preceding aerobic period, resulting in total nitrate removal within the sub-cycle. In this case, the effluent nitrate concentration could be directly controlled by the nitrification capacity of the last subcycle:

$$
S_{N O}=\left(\frac{T_{S C}}{T_{P}}\right)\left(\frac{V_{F}}{V_{T}}\right) N_{O X}
$$

This expression also provides a good indication for the fact that $\mathrm{S}_{\mathrm{NO}}$ may be lowered with a higher number of sub-cycles created within the total process phase. As far as P removal was concerned, despite efficient nitrate removal, the data displayed in Fig. 1 show that the very short anaerobic phase created in the first mixed period was not sufficient for EBPR.

\section{Effect of aeration and filling patterns}

Simulation results associated with Runs 5, 6, 7, 8 and 9, programmed with the same cycle times and $\mathrm{T}_{\mathrm{M}} / \mathrm{T}_{\mathrm{P}}$ ratios, were compared in order to evaluate the effect of aeration and filling patterns on effluent $\mathrm{N}$ and $\mathrm{P}$ concentrations. In run 5 representing a single aeration pattern, the effluent $\mathrm{S}_{\mathrm{NO}}$ was determined by the $\mathrm{V}_{0} / \mathrm{V}_{\mathrm{F}}$ ratio and both the organic carbon and the reaction time of the anaerobic phase sustained after total nitrate consumption, was sufficient for complete $\mathrm{P}$ removal. In Run 6 with a double aeration configuration, the effluent $\mathrm{S}_{\mathrm{NO}}$ was calculated to improve from $10.9 \mathrm{mg} \cdot \ell^{-1}$ to $7.8 \mathrm{mg} \cdot \ell$ ${ }^{-1}$ as available nitrate was increased independently from the $\mathrm{V}_{0} / \mathrm{V}_{\mathrm{F}}$ ratio, by means of post-denitrification leading to a more effective usage of the denitrification potential. The favourable conditions of the first mixed period persisted for an efficient EBPR. The step feeding in Run 7 involving a double mixed filling, provided a higher denitrification efficiency, yielding a further $1.5 \mathrm{mg} \cdot \ell^{-1} \mathrm{~S}_{\mathrm{NO}}$ removal, directly related to the increase in the denitrificaton potential of the second anoxic period. With the intermittent aeration and dump filling characterising Run 8, it was possible to lower the effluent $\mathrm{S}_{\mathrm{NO}}$ to $2.2 \mathrm{mg} \cdot \ell^{-1}$ as previously explained, however the very short anaerobic phase created in the first mixed period was definitely not sufficient for EBPR, an observation which may be due partly to higher nitrate removal, and partly to the lower denitrification potential associated with the adopted $\mathrm{T}_{\mathrm{M}} / \mathrm{T}_{\mathrm{P}}$ ratio, as a result of the filling pattern. Continuous filling together with the same intermittent aeration pattern in Run 9 did not affect the effluent nitrate and phosphate concentrations but exerted an influence on the concentration profiles within the cyclic operation. Continuous filling was also observed to cause a slight increase in the effluent ammonia concentration from $0.10 \mathrm{mg} \cdot \ell^{-1}$ to $0.76 \mathrm{mg} \cdot \ell^{-1}$.

\section{Effect of dissolved oxygen concentration}

In this part, the model simulation in Run 4 was repeated, (Run 4a), with identical operational conditions except for a lower DO level of $1.0 \mathrm{mg} \cdot \ell^{-1}$ associated with the aerobic phase. When only predenitrification prevails, as in Runs 1 to 5, it is generally accepted that nitrate removal is limited hydraulically by the $\mathrm{V}_{0} / \mathrm{V}_{\mathrm{T}}$ ratio, provided that the denitrification potential is sufficient to remove all available nitrate. However, a positive contribution should also be expected from denitrification likely to take place together with nitrification during the aeration period. The conventional physical explanation for this phenomenon is that simultaneous nitrification and denitrification may occur as a consequence of dissolved oxygen (DO) concentration gradients within microbial flocs, due to diffusion limitations (Münch et al., 1996). Simultaneous denitrification may proceed at a very low rate dictated by the selected values for DO concentration and the $\mathrm{K}_{\mathrm{O} 2}$ coefficient for the heterotrophs. For the DO level set to $6.0 \mathrm{mg} \cdot \ell^{-1}$ in runs 1 to 5 , a default value of $0.2 \mathrm{mg} \cdot \ell^{-1}$ for $\mathrm{K}_{\mathrm{O} 2}$ in ASM2d resulted in a denitrification rate during the aerobic phase, corresponding to $3 \%$ to what was normally achieved under anoxic conditions. With the DO level of $1.0 \mathrm{mg} \cdot \ell^{-1}$ in Run $4 \mathrm{a}$, this ratio increased to $17 \%$, together with a lower nitrification rate reduced by a factor of $\mathrm{S}_{\mathrm{O} 2} /$ $\left(\mathrm{S}_{\mathrm{O} 2}+\mathrm{K}_{\mathrm{O} 2 \mathrm{~A}}\right)$ which was calculated as 0.67 for $\mathrm{S}_{\mathrm{O} 2}=1.0 \mathrm{mg} \cdot \ell^{-1}$ and a default $\mathrm{K}_{\mathrm{O} 2, \mathrm{~A}}=0.5 \mathrm{mg} \cdot \ell^{-1}$. Since the aerated phase was long enough for full nitrification in both Runs 4 and $4 \mathrm{a}$, the lower DO concentration of $1.0 \mathrm{mg} \cdot \ell^{-1}$ was observed to induce only a minor increase in the effluent $\mathrm{S}_{\mathrm{NH}}$ values, coupled with a substantial $\mathrm{S}_{\mathrm{NO}}$ difference of $2.2 \mathrm{mg} \cdot \ell^{-1}$, due to additional denitrificaton. Simulation results also showed that effluent $\mathrm{S}_{\mathrm{NO}}$ values for all predenitrification runs could be predicted as $\left(\mathrm{N}_{\mathrm{OX}}-\mathrm{N}_{\mathrm{A}}\right)$ with an acceptable approximation, except for Run $4 \mathrm{a}$.

\section{Effect of COD/TKN ratio}

Evaluations in the preceding parts demonstrated that the selected wastewater composition with a high COD/TKN ratio of 10.4 was greatly suitable for effective nutrient removal in SBR systems with the selection of an appropriate process configuration. However this ratio may not be so typical for domestic sewage in many countries, and lower values are often reported in the literature (Orhon et al., 1997). In this context, Run 3a was simulated in conjunction with Run 3, with the only difference that the influent TKN level was increased to $37 \mathrm{mg} \cdot \ell^{-1}$ corresponding to a lower COD/TKN ratio of 7. As shown by the data displayed in Fig. 1 and Table 2, the change directly reflected on the effluent $S_{\text {NO }}$ level increasing from 10.9 $\mathrm{mg} \cdot \ell^{-1}$ to $17.6 \mathrm{mg} \cdot \ell^{-1}$, as a natural consequence of a higher $\mathrm{N}_{\mathrm{Ox}}$ generated with the new influent TKN level. The additional $\mathrm{N}_{\mathrm{A}}$ introduced into the mixed period consumed a larger fraction of the organic carbon source for denitrification and consequently the effluent $\mathrm{P}$ concentration was observed to change from $0.65 \mathrm{mg} \cdot \ell^{-1}$ to $2.92 \mathrm{mg} \cdot \ell^{-1}$, as the remaining COD was not sufficient and suitable for EBPR. The effect of the magnitude and the composition of COD on EBPR is a much more complex problem, dealt with in detail in the literature (Tasli et al., 1997; 1999).

\section{Effect of COD/TP ratio}

An SBR system operated with the selected standard wastewater composition yielding a COD/TP ratio of 43 in Runs 5 and 6 was calculated to secure an effluent $\mathrm{S}_{\mathrm{PO} 4}$ of $0.5 \mathrm{mg} \cdot \ell^{-1}$, through effective EBPR and substantial $N$ removal. In order to investigate whether the system has further EBPR capacity, the influent TP concentration 


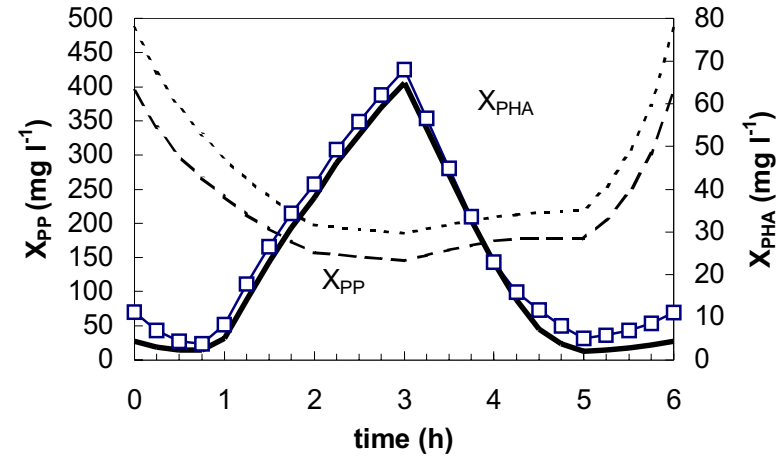

$\begin{array}{ll}---\operatorname{run} 5 & \cdots \cdot \operatorname{run} 5 a \\ - & \end{array}$



$---\operatorname{run} 5$

$\cdots-\operatorname{run} 5 a$

a: Runs 5 (Inf TP: $\left.6 \mathrm{mg} \cdot \ell^{-1}\right)$ and $5 a\left(\operatorname{lnf} \mathrm{TP}: 9 \mathrm{mg} \cdot \ell^{-1}\right)$
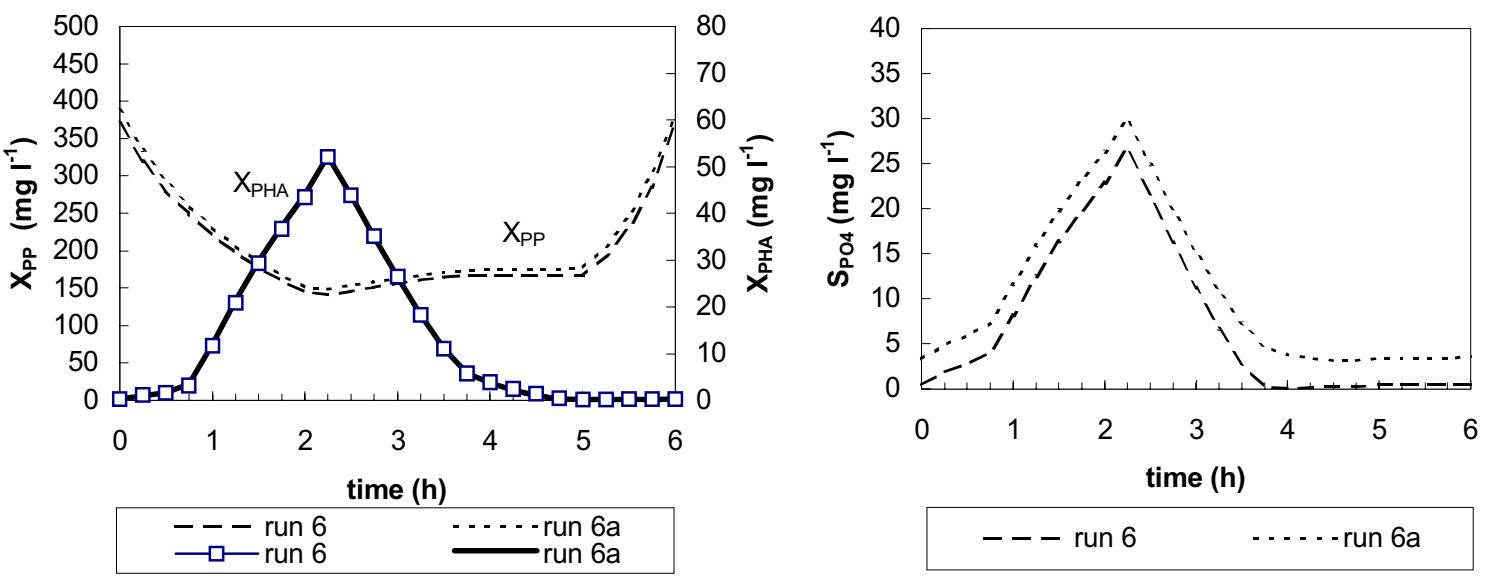

b: Runs 6 (Inf TP: $6 \mathrm{mg} \cdot \ell^{-1}$ ) and $6 a\left(\operatorname{lnf} \mathrm{TP}: 9 \mathrm{mg} \cdot \ell^{-1}\right)$

Figure 2

Effect of COD/TP ratio on $S_{P O 4}, X_{P P}$ and $X_{P H A}$ concentration profiles
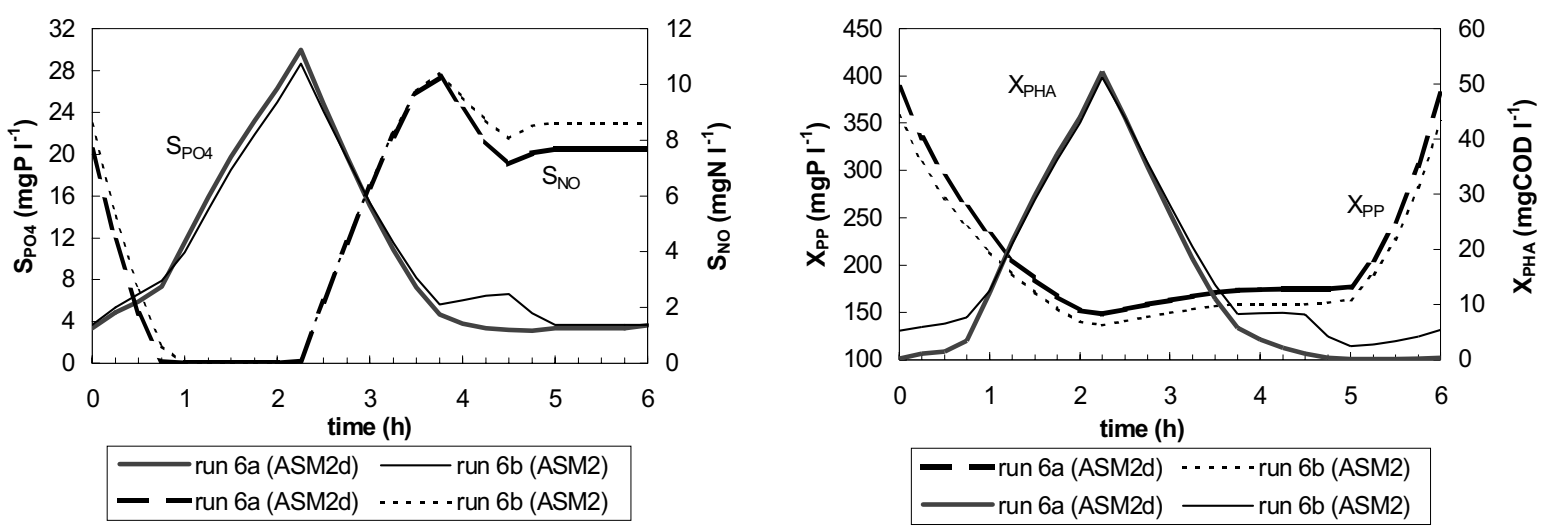

Figure 3

Comparison of ASM2d (Run 6a) and ASM2 (Run 6b)

was increased to $9 \mathrm{mg} \cdot \ell^{-1}$ (a $3 \mathrm{mg} \cdot \ell^{-1}$ increase) in Runs $5 \mathrm{a}$ and $6 \mathrm{a}$, corresponding to a COD/TP ratio of 30 .

Two different conditions reflecting $\mathrm{P}$ limitation and $\mathrm{P}$ storage capacity limitation should be envisaged for evaluating the effect of $\mathrm{COD} / \mathrm{TP}$ ratio on EBPR. In the case of $\mathrm{P}$ limitation, indicating that the system still has an additional EBPR potential, increasing the $\mathrm{P}$ level for a given COD concentration and composition in the influent, will not seriously affect the effluent $\mathrm{S}_{\mathrm{PO} 4}$ level until the existing $\mathrm{P}$ storage capacity is exceeded. The system will respond with a corresponding increase in the PP concentration and in the $\mathrm{P}$ 


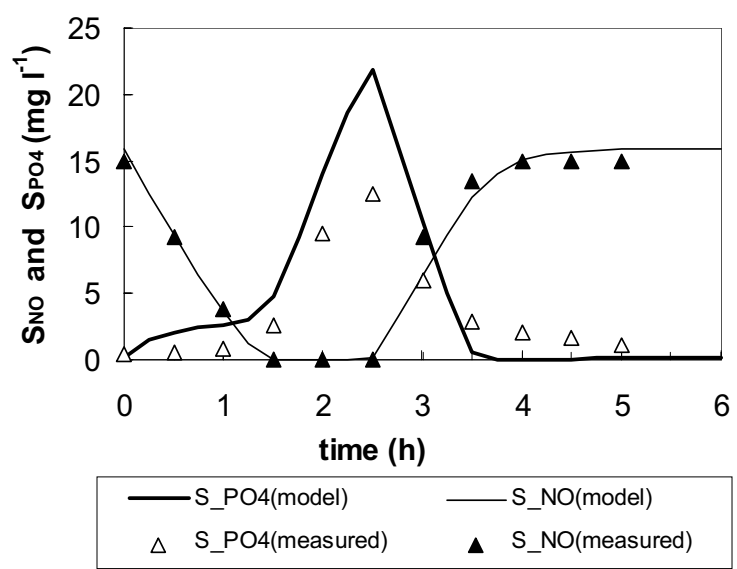

Figure 4

Comparison of simulated and measured values of $S_{N O}$ and $S_{P O 4}$

content of the activated sludge. This situation is partly illustrated with Runs 5 and 5a: Simulation results for Run 5a reveal that the increase in the effluent $\mathrm{S}_{\mathrm{PO} 4}$ was less than the change imposed on the influent $\mathrm{S}_{\mathrm{PO} 4}$, indicating that the system had an available EBPR capacity before the change in the $\mathrm{COD} / \mathrm{TP}$ ratio. In fact, towards the end of the aerobic period, a decrease in the rate of PHA consumption could be observed due to P limitation, from the PHA concentration profiles of Run 5, displayed in Fig 2a. The same figure also shows a significant increase in the PP concentration, along with a compatible increase in the $\mathrm{P}$ content of the activated sludge from $6.5 \%$ to $7.4 \%$, as given in Table 2 .

In the case of $\mathrm{P}$ storage capacity limitation, an increase in the influent $\mathrm{S}_{\mathrm{PO} 4}$ concentration will reflect entirely on the effluent, as the system has no biochemical tools to remove the additional $\mathrm{P}$ input. This situation was simulated with Run 6a, where the effluent $\mathrm{S}_{\mathrm{PO} 4}$ increased nearly $3 \mathrm{mg} \cdot \ell^{-1}$ as could be seen in Table 2 and Fig. $2 \mathrm{~b}$. No differences in PHA concentration profiles, with a very minor increase in PP concentration and in the P content of the sludge, were observed as compared to Run 6 . These results give a clear indication of a COD limitation under adopted operating conditions.

\section{Effect of denitrifying PAOs}

The ASM2d model incorporates a correction factor, $\eta_{\mathrm{NO} 3}$ with a default value of 0.6 , which reflects the assumption that $60 \%$ of the PAOs possess denitrification capability. In order to demonstrate the effect of this additional denitrification capacity on nutrient removal performance, the simulation for Run 6a with two anoxic periods was repeated as Run $6 \mathrm{~b}$, using the original ASM2 model where the metabolic activities of PAOs were defined with no potential for denitrification. Without this potential in Run $6 \mathrm{~b}$, ASM2 was observed to yield a higher effluent $\mathrm{S}_{\mathrm{NO}}$ of $8.6 \mathrm{mg} \cdot \ell^{-1}$ compared to $7.7 \mathrm{mg} \cdot \ell^{-1}$ in Run 6a, with a similar increase in $\mathrm{S}_{\mathrm{PO} 4}$ from $3.36 \mathrm{mg} \cdot \ell^{-1}$ to $3.69 \mathrm{mg} \cdot \ell^{-1}$ as shown in Table 2 and Fig. 3. Figure 3 also exhibits for Run 6a, a slightly lower phosphate concentration at the end of the first anoxic period, as compared to Run $6 \mathrm{~b}$, an observation that may be attributed to the anoxic $\mathrm{P}$ uptake of denitrifying PAOs. As a smaller amount of nitrate was introduced into the first mixed period, a longer anaerobic phase could be sustained, causing a slight increase in P release. Since there was no filling and acetate to be stored in the second anoxic period of Run $6 a$, release was lower than uptake, resulting in a net phosphate uptake. In Run $6 \mathrm{~b}$ however, the second anoxic period could be considered as anaerobic as far as metabolic activities of PAOs were concerned, leading to a secondary $\mathrm{P}$ release, thus necessitating a successive aerobic period for improving the effluent $\mathrm{P}$ level, through $\mathrm{P}$ uptake. The data shows that, despite the $\mathrm{P}$ uptake in the following aerobic period, a slightly higher effluent $\mathrm{S}_{\mathrm{PO} 4}$ was observed compared to Run 6a. The interpretation of PHA profiles in Fig. 3 provides a clearer evidence on the effect of denitrifying PAOs, since the assumption that PAOs cannot denitrify should be interpreted as PHA consumption is not likely to take place in the anoxic periods.

\section{Effect of model coefficients}

Although modelling is a very convenient tool for evaluation, the merit of model simulation is entirely dependent on the validity of values selected for the various model constants. The expected performance of an SBR system for a specific wastewater is bound to relate to pertinent wastewater characteristics and model constants that best describe the selected wastewater. It should be noted that default values for model constants suggested together with ASM2d were adopted in this study, mainly because the objective was not to provide experimental proof to model simulations. Such an approach would be too wastewater specific and therefore, not compatible with the conceptual/theoretical evaluation of process performance for nutrient removal.

Nevertheless, as a demonstration of the prediction capacity of the model, data from a lab scale SBR fed with Istanbul sewage were compared to the simulation results obtained, using concentrations of model components in this wastewater and default values of kinetic and stoichiometric coefficients. The influent wastewater composition after the supplementation of $150 \mathrm{mg} \cdot \ell^{-1}$ acetate consisted of total $\mathrm{COD}=360 \mathrm{mg} \cdot \ell^{-1}$, TKN $=45 \mathrm{mg} \cdot \ell^{-1}$ and $\mathrm{TP}=8 \mathrm{mg} \cdot \ell^{-1}$. SBR was operated in a pre-denitrification mode under the same conditions as those in Run 3 except for higher $\mathrm{V}_{0} / \mathrm{V}_{\mathrm{F}}$ ratio of 1.65. Simulated nitrate concentration profile perfectly matched the measured values whereas phosphate concentrations did not (Fig. 4). These results imply that model coefficients related to EBPR need to be calibrated or the phosphorus part of the model should be improved.

\section{Conclusions}

The conclusions of this study, based upon model simulations and evaluations outlined in the preceding sections, may be summarised as follows:

Comprehensive models, such as ASM2d used in this study, provide an acceptable mechanistic description of the array of processes defining nutrient removal in activated sludge systems. Performance evaluation through modelling of SBR behaviour is particularly interesting as it yields, aside from information on the expected effluent quality, transients in concentration profiles of selected significant parameters for different phases that can be sustained within the cyclic operation of the SBR.

Model simulation of SBR performance generates data for a given set of operating conditions. Repeating the simulation exercise for the desired number of different parameter combinations may expand collected data, each one corresponding to a different SBR operation. However, understanding and interpretation of the model outputs for performance prediction and system optimisation can only be achieved when the simulation is evaluated in the light of basic process stoichiometry. Nutrient removal in SBRs, as in all biological systems, depends upon a delicate balance between 
nitrification capacity, $\mathrm{N}_{\mathrm{OX}}$, denitrification potential, $\mathrm{N}_{\mathrm{DP}}$, and nitrate concentration introduced in the mixed period(s), $\mathrm{N}_{\mathrm{A}}$. This balance is numerically indicative for all nitrogen transformations. A similar approach is not yet possible for EBPR, due to the complexity of the biochemical processes involved. It may be partly realised, as illustrated in this study, using indirect information on relevant parameters such as the extent of nitrogen removal, the remaining P storage capacity, etc.

Validity of simulation results for performance prediction depends upon the values selected for different kinetic and stoichiometric coefficients associated with a wide spectrum of biochemical processes defined in the model. The results obtained will be of direct consequence of the values selected. Therefore, appropriate calibration of the model for specific wastewaters of interest is recommended as a significant area for future work. SBR operation for nutrient removal is observed to possess striking similarities with major continuous-flow activated sludge configurations. SBR performance also benefits from additional operational features such as sequential use of different aeration and filling patterns, resulting from the flexibility inherently associated with the system. However, strategies to prevent nitrate from utilising readily biodegradable carbon in the influent stream must be different from continuous-flow systems as different schemes of internal recycle is not possible with SBR. Thus, an anoxic period is inherently established prior to anaerobic phase due to introduction of nitrate with sludge recycle into the first mixed period. Results related to SBR behaviour and basic process stoichiometry.

Selection of a desired cycle time, $T_{C}$, provides $S B R$ with further flexibility. This way, SBR can be adjusted to operate with different recycle ratios for the same hydraulic retention time. If nitrogen removal without EBPR is the main objective, the system should be operated with the shortest possible cycle time at high recycle ratios. If however, EBPR along with $\mathrm{N}$ removal is required, longer cycle time should be selected in order to operate with minimum (sludge) recycle ratio. High nitrate removal with EBPR can be achieved with a dual or triple mixed filling. Although a part of the denitrification potential is wasted when applied, continuous filling may still be preferable for a simpler operation mode, especially for wastewaters with high $\mathrm{COD} / \mathrm{N}$ ratio.

\section{Acknowledgments}

This study was conducted as part of the sponsored research activities of The Environmental Biotechnology Centre of the Scientific and Research Council of Turkey. It was also supported by The Research and Development Fund of Istanbul Technical University.

\section{References}

ARTANN, ORHOND and SÖZENS (1995) Conceptual basis of wastewater nitrogen removal in sensitive coastal areas. Water Sci. Technol. 32 (11) 77-84.

ARTAN N, AKKAYA M and ARTAN S.R. (1996) Experiences with the SBR treatment of industrial wastewaters. Proc. First IAWQ Specialized Conference on SBR Technology, 197 - 204, Munich.
ARTAN N, TA^LI R, ÖZGÜR N and ORHON D (1998) The fate of phosphorus under anoxic conditions in biological nutrient removal activated sludge systems. Biotechnol. Lett. 20 (11) 1085 - 1090.

ARTAN N, WILDERER P, ORHON D, MORGENROTH E and ÖZGÜR $\mathrm{N}$ (2001) The mechanism and design of sequencing batch reactor systems for nutrient removal - The state of the art, Water Sci. Technol. 43 (3) 53-60.

BARKER P S and DOLD P L (1997) General model for biological nutrient removal activated - sludge systems: Model presentation. Water Environ. Res. 69 (5) 969-984.

EKAMA G A and WENTZEL M C (1999) Difficulties and developments in biological nutrient removal technology and modelling. Water. Sci. Technol. 39 (6) 1-11.

GORONSZY M C (1995) Large scale application of cyclically operated activated sludge technology. In proceedings $7^{\text {th }}$ International conference on design and operation of large treatment plants. Viena.

HENZE M, GUJER W, MINO T, MATSUO T, WENTZEL M C and MARAIS G v R (1995) Activated Sludge Model No.2 IAWQ Scientific and Technical Report No:3. IAWQ London. 32 pp.

HENZE M, GUJER W, MINOT, MATSUOT, WENTZEL MC, MARAIS G v R and VAN LOOSDRECHT M C M (1999) Activated sludge model No 2d. ASM2d. Water Sci. Technol. 39 (1) 165-183.

IRVINE RL, WILDERER P A and FLEMMING H C (1997) Controlled unsteady state processes and technologies-an overview. Water Sci. Technol. 35 (1) 1-10.

KETCHUM L H Jr (1997) Design and physical features of sequencing batch reactors. Water Sci. Technol. 35 (1) 11-18.

KUBA T, VAN LOOSDRECHT M C M, BRANDSE F A and HEIJEN J $J$ (1997) Occurrence of denitrifying phosphorus removing bacteria in modified UCT-type wastewater treatment plants. Water Res. 31 (4) 777-786.

MINO T, LIU W T, KURISU F and MATSUO T (1995) Modeling glycogen storage and denitrification capability of microorganisms in enhanced biological phosphate removal processes. Water Sci. Technol. 31 (2) 25-34.

MORGENROTHE and WILDERER P A (1998) Sequencing batch reactor technology-Concepts, design, experience. J. CIWEM, 12 (5) 314-321.

MÜNH E V, LANT P and KELLER J (1996) Simultaneous nitrification and denitrification in bench-scale sequencing batch reactors, Water Res. 30 (2) 277-284.

ORHON D and ARTAN N (1994) Modelling of Activated Sludge Systems. Technomic Publ. Co. Inc., Lancaster, Basel.

ORHON D, ATES E, SÖZEN S and UBAY ÇOKGÖR E (1997) Characterization and COD fractionation of domestic wastewaters, Environ. Pollut. 95 (2) 191-203.

REICHERT P(1994) AQUASIM-A Tool for simulation and data analysis of aquatic systems. Water Sci.Technol. 30 (2) 21-30.

SORM R, BORTONE G, SALTARELLI R, JENICEK P, WANNER J and TILCHE A (1996) Phosphate uptake under anoxic conditions and fixed - film nitrification in nutrient removal activated sludge system. Water Res. 30(7) 1573-1584.

TASLI R, ARTAN N and ORHON D (1997) The influence of different substrates on enhanced biological phosphorus removal (EBPR) in a sequencing batch reactor, Water Sci Technol. 35 (1) 75-80.

TASLI R, ORHON D and ARTAN N (1999) The effect of substrate composition on the nutrient potential of sequencing batch reactors. Water SA, 25 (3) 337 - 344.

WILDERER P A, IRVINE R L, GORONSZY M C, ARTAN N, DEMOULIN G, KELLER J, MORGENROTH E, NYHUIS G, TANAKA K and TORRIJOS M (2001) Sequencing Batch Reactor Technology, IWA Scientific and Technical Report No:10, London. 